\title{
INFLUÊNCIA DOS CONSTITUINTES QUÍMICOS DOS EXTRATOS DE DIFERENTES MATRIZES NA RESPOSTA CROMATOGRÁFICA DE AGROTÓXICOS
}

\author{
Gevany Paulino de Pinho* e Flaviano Oliveira Silvério \\ Instituto de Ciências Agrárias, Universidade Federal de Minas Gerais, 39404-006 Montes Claros - MG, Brasil \\ Antônio Augusto Neves, Maria Eliana L. R. Queiroz e Maria Antônia V. M. Starling \\ Departamento de Química, Universidade Federal de Viçosa, 365770-000 Viçosa - MG, Brasil
}

Recebido em 9/9/09; aceito em 12/12/09; publicado na web em 26/3/10

\begin{abstract}
INFLUENCE OF THE CHEMICAL CONSTITUENTS OF EXTRACTS FROM DIFFERENT MATRICES IN THE PESTICIDE CHROMATOGRAPHIC RESPONSE. Multiresidue methods for pesticides monitoring by GC are commonly employed, however, it is well known that the presence of compounds of the matrix introduces errors during the quantification. The main consequence of matrix effect is an increasing or decreasing analyte signal after the GC saturation with extracts of matrix. In this paper, the influence of constituents of nine matrices on the quantification of the four pesticides by GC-ECD was studied. Variation of signal was evaluated by PCA and HCA, and results showed that the constituents of tomato increased the signal (until 300\%), while extracts of apple decreased (until -20\%). Variation the analyte signal in the presence of the matrix in respect to the same analyte in solvent (standard solution) also was observed, mainly for liver extract (until 270\%).
\end{abstract}

Keywords: matrix effect; pesticides; PCA.

\section{INTRODUÇÃO}

A cromatografia gasosa (CG) é seguramente a técnica mais utilizada para análise de resíduos de agrotóxicos em diversas matrizes ambientais. Isso se deve ao elevado potencial de separação de compostos em misturas complexas e ao baixo limite de detecção alcançado pelos detectores convencionais de CG. ${ }^{1}$ Entretanto, durante as análises cromatográficas os componentes da matriz contidos nos extratos podem influenciar na quantificação dos analitos de interesse, gerando resultados duvidosos. Este fenômeno é denominado de aumento da resposta cromatográfica induzida pelos componentes da matriz ou efeito de matriz., ${ }^{2,3}$

O efeito de matriz é dependente das propriedades físico-química dos agrotóxicos e das características dos componentes endógenos da matriz (tamanho das moléculas, polaridade, estabilidade térmica, pressão de vapor, etc) ${ }^{2,4-6}$ Para minimizar a influência dos componentes da matriz na quantificação de agrotóxicos são utilizadas estratégias como limpeza dos extratos, ${ }^{5}$ injeção no topo da coluna, ${ }^{3,7}$ e injeção com temperatura programada de vaporização. ${ }^{8-10}$ Também existem os procedimentos que promovem a compensação da ocorrência do efeito de matriz como a utilização de analitos protetores, ${ }^{11-13}$ função de correção, ${ }^{14,15}$ adição de padrão ${ }^{16}$ e curva analítica preparada pela dissolução dos padrões em extratos da matriz. ${ }^{17,18}$

Dentre os diversos métodos empregados para minimizar o efeito de matriz, a limpeza dos extratos (clean up) é o único que efetivamente elimina a causa do problema, ou seja, a remoção dos componentes da matriz. Após a extração dos analitos técnicas auxiliares são utilizadas para remoção de coextrativos (pigmentos, lipídios, carboidratos, etc.) como, por exemplo, extração em fase sólida, ${ }^{19,20}$ extração líquido-líquido e cromatografia por permeação em gel. ${ }^{21}$ Além dessas técnicas existem também as que proporcionam a extração dos analitos e a limpeza dos extratos simultaneamente, como a dispersão da matriz em fase sólida $(\mathrm{DMFS})^{22,23} \mathrm{e}$, mais recentemente, a extração sólido-líquido com purificação em baixa temperatura (ESL-PBT). ${ }^{24,25}$ Entretanto, a remoção exaustiva dos componentes da matriz pode conduzir à baixa taxa de recuperação dos agrotóxicos, o que torna as técnicas de purificação inadequadas para análises quantitativas.

*e-mail: gevanypp@yahoo.com.br
Dessa forma, os métodos de extração existentes não eliminam definitivamente os coextrativos, e a presença destes compostos remanescentes proporciona alterações da resposta cromatográfica. Por exemplo, baixas respostas são obtidas em análises de agrotóxicos termodegradáveis preparados em solventes, entretanto, as respostas são mais intensas quando estes compostos são analisados a partir de extratos contendo carboidratos, proteínas e lipídios, obtidos a partir da extração líquido-líquido (ELL) e limpeza com extração em fase sólida (EFS). ${ }^{26}$

Mastovska e colaboradores avaliaram o efeito de matriz por comparação das respostas cromatográficas de agrotóxicos preparados em solvente com as respostas dos mesmos compostos em misturas de extratos de frutas (maçã, uva, pêssego e ameixa) e misturas de extratos de vegetais (couve-flor, tomate, pepino e pimentão) por CG-EM. ${ }^{27}$ Embora a estratégia de utilizar extratos representativos tenha mostrado ser prática, os componentes de cada matriz podem interferir diferentemente na análise cromatográfica. Por exemplo, pode ocorrer aumento no sinal do detector, levando à superestimação do resultado. Isso ocorre quando impurezas voláteis são eluídas com mesmo tempo de retenção dos agrotóxicos. Também pode ocorrer extinção do sinal no detector, ou seja, o sinal do analito é diminuído gerando uma subestimação do resultado, fato comum aos detectores fotométricos de chama. ${ }^{28}$

Nesse sentido, Przybylski e Hommet ${ }^{29}$ fizeram uma comparação entre os coeficientes angular das curvas analíticas obtidas a partir de soluções-padrão de 12 agrotóxicos preparadas em solvente e em extratos de cinco matrizes individuais (cenoura, alimento infantil, feijão verde, batata e ervilha). Os resultados indicaram que o efeito de matriz quantificado pelos coeficientes angulares das curvas analíticas (razão entre coeficientes angulares matriz/solvente) pode ser positivo (razão $>1$ ) ou negativo (razão $<1$ ), dependendo das características dos agrotóxicos e da complexidade da matriz em análise por cromatografia gasosa.

Este trabalho teve como objetivo avaliar a influência dos componentes presentes nos extratos de nove matrizes - tomate, leite, maçã, mel, solo, batata, fígado, alcatra e água - nas respostas cromatográficas de quatro agrotóxicos, clorpirifós, $\lambda$-cialotrina, cipermetrina e deltametrina, comumente encontrados nestes tipos de amostras. As porcentagens de variação das respostas cromatográficas dos agrotóxicos em cada amostra foram submetidas à análise de componentes principais (ACP) e análise 
hierárquica de agrupamentos (AHA), a fim de se verificar a utilidade das análises quimiométricas no estudo do efeito de matriz. ${ }^{30}$

\section{PARTE EXPERIMENTAL}

\section{Reagentes}

Soluções padrão estoque de clorpirifós $(99,0 \% \mathrm{~m} / \mathrm{m})$, cipermetrina $(92,4 \% \mathrm{~m} / \mathrm{m})$ e deltametrina $(99,0 \% \mathrm{~m} / \mathrm{m})$, obtidos da Chem Service (West Chester, PA, USA), e $\lambda$-cialotrina $(86,5 \% \mathrm{~m} / \mathrm{m})$, obtida da Syngenta (São Paulo, Brasil), foram preparadas em acetonitrila na concentração de 500,0 mg L $\mathrm{mg}^{-1}$ e armazenadas em temperatura de $4{ }^{\circ} \mathrm{C}$. A partir da diluição das soluções estoque, foram preparadas duas soluções contendo os quatros agrotóxicos em concentrações de 50,0 e 5,0 $\mathrm{mg} \mathrm{L}^{-1}$ no mesmo solvente. $\mathrm{O}$ mesmo procedimento foi empregado para o preparo da solução de bifentrina (92,2\% m/m - FMC do Brasil), 5,0 $\mathrm{mg} \mathrm{L}^{-1}$, utilizada como padrão interno.

Como solventes foram utilizados acetato de etila para análises de traços da Merck (Darmastadt, Alemanha) e acetonitrila da Mallinckrodt/ HPLC (Paris, França). Sulfato de sódio anidro com grau de pureza superior a $99 \%$ foi adquirido da Vetec (Rio de Janeiro, Brasil). Florisil (J. T. Baker) foi condicionado com acetonitrila e acetato de etila e secado em estufa em $45^{\circ} \mathrm{C}$.

\section{Procedimento analítico}

Preparo dos extratos orgânicos de amostras por extração sólidolíquido e extração líquido-líquido com purificação em baixa temperatura (ESL-PBT e ELL-PBT)

Extratos orgânicos de amostras de tomate, maçã, solo, batata, fígado e alcatra e extratos orgânicos de amostras de leite, mel e água foram obtidos a partir das técnicas de ESL-PBT e ELL-PBT, respectivamente. ${ }^{24,25,31-35}$ Para isso, uma determinada quantidade da amostra (Tabela 1) foi transferida para frasco de vidro transparente $(22 \mathrm{~mL})$ e, em seguida, foi adicionada à mistura extratora (Tabela 1). $\mathrm{O}$ sistema foi submetido à homogeneização (Tabela 1) e resfriado em freezer a $-20^{\circ} \mathrm{C}$ por $6 \mathrm{~h}$. Após este período, foi obtido um sistema bifásico constituído da fase

Tabela 1. Descrição do preparo dos extratos de nove matrizes empregando ELL-PBT e ESL-PBT: quantidade de amostra, composição da mistura extratora e forma de homogeneização

\begin{tabular}{|c|c|c|c|c|c|c|}
\hline \multirow[b]{2}{*}{$\mathrm{N}^{\circ}$} & \multicolumn{6}{|c|}{ Mistura extratora } \\
\hline & Matriz & Quant. & Acetonit. & Acet. de etila & Água & Homogeneização \\
\hline 1 & Alcatra $^{34}$ & $3,0 \mathrm{~g}$ & $6,5 \mathrm{~mL}$ & $1,5 \mathrm{~mL}$ & $1,0 \mathrm{~mL}$ & $\begin{array}{l}\text { Ultrassom } \\
(10 \mathrm{~min})\end{array}$ \\
\hline 2 & Água ${ }^{31}$ & $4,0 \mathrm{~mL}$ & $6,5 \mathrm{~mL}$ & $1,5 \mathrm{~mL}$ & - & $\begin{array}{l}\text { Mesa agitadora } \\
\quad(15 \mathrm{~min})\end{array}$ \\
\hline 3 & Fígado ${ }^{34}$ & $3,0 \mathrm{~g}$ & $8,0 \mathrm{~mL}$ & - & $1,0 \mathrm{~mL}$ & $\begin{array}{l}\text { Ultrassom } \\
\text { (10 min) }\end{array}$ \\
\hline 4 & Leite $^{24}$ & $4,0 \mathrm{~mL}$ & $8,0 \mathrm{~mL}$ & - & - & $\begin{array}{l}\text { Mesa agitadora } \\
\quad(20 \mathrm{~min})\end{array}$ \\
\hline 5 & Maçãa, $\tilde{a}^{a, 35}$ & $3,0 \mathrm{~g}$ & $8,0 \mathrm{~mL}$ & - & $1,0 \mathrm{~mL}$ & $\begin{array}{c}\text { Mesa agitadora } \\
\quad(30 \mathrm{~min})\end{array}$ \\
\hline 6 & Solo 31 & $1,0 \mathrm{~g}$ & $6,5 \mathrm{~mL}$ & $1,5 \mathrm{~mL}$ & $4,0 \mathrm{~mL}$ & $\begin{array}{l}\text { Ultrassom } \\
\text { (20 min) }\end{array}$ \\
\hline 7 & $\mathrm{Mel}^{\mathrm{a}, 32}$ & $3,0 \mathrm{~g}$ & $6,5 \mathrm{~mL}$ & $1,5 \mathrm{~mL}$ & $4,0 \mathrm{~mL}$ & $\begin{array}{l}\text { Vortex } \\
(30 \mathrm{~s})\end{array}$ \\
\hline 8 & Batata $^{33}$ & $3,0 \mathrm{~g}$ & $6,5 \mathrm{~mL}$ & $1,5 \mathrm{~mL}$ & $1,0 \mathrm{~mL}$ & $\begin{array}{l}\text { Ultrassom } \\
\text { (10 min) }\end{array}$ \\
\hline 9 & Tomate $^{25}$ & $4,0 \mathrm{~g}$ & $8,0 \mathrm{~mL}$ & $1,5 \mathrm{~mL}$ & $0,5 \mathrm{~mL}$ & $\begin{array}{l}\text { Ultrassom } \\
\text { (10 min) }\end{array}$ \\
\hline
\end{tabular}

${ }^{a}$ Extratos orgânicos líquidos foram eluidos através de uma coluna contendo 2,00 $\mathrm{g}$ de florisil e 1,50 de sulfato de sódio anidro. sólida (congelamento da fase aquosa e da matriz) e da fase líquida (sobrenadante). Este líquido foi passado por 1,50 g de sulfato de sódio anidro. O filtrado obtido (extrato) foi recuperado em balão volumétrico de 10,0 mL, com acetonitrila e a solução foi armazenada no freezer, até o momento da análise por CG-DCE. Na Tabela 1 são descritas as condições específicas para o preparo de cada amostra.

\section{Equipamentos e condições de análises}

\section{Equipamentos de laboratório}

Foi utilizado um banho ultrassônico da Unique (São Paulo, Brasil) durante o preparo das amostras. O gerador deste banho tem uma saída de $150 \mathrm{~W}$ e uma frequência de $25 \mathrm{kHz}$. Também foi utilizada uma mesa agitadora (Tecnal TE - 420, São Paulo, Brasil) a $25^{\circ} \mathrm{C}$ e 175 oscilações por minuto e um vortex.

\section{$C G-D C E$}

Foi utilizado um cromatógrafo a gás da Shimadzu (GC-2014) equipado com um detector por captura de elétrons (DCE) e uma coluna capilar HP-5 da Agilent Technologies, com fase estacionária composta de $5 \%$ fenilmetilsiloxano e $95 \%$ dimetilsiloxano (30 $\mathrm{m}$ x $0.25 \mathrm{~mm}$ d.i., $0,1 \mu \mathrm{m}$ de espessura do filme), sendo nitrogênio o gás de arraste (1,2 $\left.\mathrm{mL} \mathrm{min}^{-1}\right)$. As temperaturas do injetor e detector foram 280 e $300{ }^{\circ} \mathrm{C}$, respectivamente. A coluna inicialmente a $150{ }^{\circ} \mathrm{C}$ foi aquecida a $10^{\circ} \mathrm{C}$ $\min ^{-1}$ até $290^{\circ} \mathrm{C}$, permanecendo nessa temperatura por $1 \mathrm{~min}$. Foi injetado $1 \mu \mathrm{L}$ de amostra no cromatógrafo a uma razão de divisor de 1:5.

\section{Avaliação da resposta cromatográfica dos agrotóxicos após saturação do CG}

Avaliou-se o efeito da saturação do sistema cromatográfico por componentes das matrizes nas respostas dos agrotóxicos clorpirifós, $\lambda$-cialotrina, cipermetrina e deltametrina. Soluções padrão dos agrotóxicos a $50 \mu \mathrm{g} \mathrm{L}^{-1}$, preparadas em acetonitrila, foram injetadas sucessivamente no CG-DCE (5 repetições) e determinou-se a área média do sinal de cada agrotóxico $\left(\overline{\mathrm{A}}_{\text {Antes }}\right)$. Em seguida, o sistema cromatográfico foi saturado com 5 injeções sucessivas de extratos orgânicos de uma determinada matriz (alcatra, água, fígado, leite, maçã, solo, mel, batata e tomate). Novamente, a mesma solução padrão a $50 \mu \mathrm{g} \mathrm{L}^{-1}$ foi injetada (5 repetições) e determinou-se a área média do sinal de cada agrotóxico $\left(\overline{\mathrm{A}}_{\text {Após }}\right)$.

\section{Análise das componentes principais (ACP)}

Para reduzir o número das variáveis (componentes principais) mais significativas, os valores da porcentagem de variação das respostas cromatográficas dos agrotóxicos (obtidos no item anterior) foram transformados em uma matriz. Essa matriz apresentou nove objetos (tipos de extratos, linhas) e quatro variáveis (agrotóxicos, colunas). Os dados foram autoescalonados e, em seguida, foram submetidos à análise das componentes principais (ACP) usando-se o software PLS-Toolbox (versão 2.1, Engenvector Research, Inc., USA).

\section{Curvas analíticas}

Foram preparadas curvas analíticas utilizando o método da padronização interna. Dez séries de soluções padrão contendo os quatro agrotóxicos nas concentrações de 5; 20; 50; $100 ; 300$ e $500 \mu \mathrm{g} \mathrm{L}{ }^{-1}$ foram preparadas. A primeira série foi obtida pela diluição das soluções de trabalho (50 e $5 \mathrm{mg} \mathrm{L}^{-1}$ ) contendo os quatro agrotóxicos em acetonitrila. Outras nove séries de soluções padrão foram preparadas por diluições das mesmas soluções de trabalho ( 50 e $\left.5 \mathrm{mg} \mathrm{L}^{-1}\right)$ em extratos de amostras individuais (alcatra, água, fígado, leite, maçã, solo, mel, batata e tomate) 
em duplicata. Estes extratos foram obtidos a partir da ESL-PBT ou ELLPBT de amostras isentas de resíduos de agrotóxicos.

\section{RESULTADOS E DISCUSSÃO}

\section{Variação da resposta cromatográfica após saturação do CG}

Após a saturação do CG com extratos orgânicos de alcatra, água, fígado, leite, maçã, solo, mel, batata e tomate as respostas cromatográficas dos agrotóxicos, em acetonitrila, variaram entre - 20 e 300\% (Tabela 2). Essas porcentagens de variação das áreas dos agrotóxicos foram determinadas empregando-se a equação [\% $\left.=\left(\overline{\mathrm{A}}_{\text {Após }}-\overline{\mathrm{A}}_{\text {Antes }}\right) / \overline{\mathrm{A}}_{\text {Antes }} \mathrm{x} 100\right]$. $\mathrm{O}$ termo $\overline{\mathrm{A}}_{\text {Após }}$ corresponde à área média do sinal do agrotóxico obtida após saturação do sistema cromatográfico. De forma semelhante, o termo $\overline{\mathrm{A}}_{\text {Antes }}$ corresponde à área média obtida antes da saturação do sistema cromatográfico.

Tabela 2. Porcentagens de variação das respostas cromatográficas dos agrotóxicos obtidas após a saturação do CG-DCE com 9 extratos de matriz

\begin{tabular}{lccccc}
\hline ACP & Amostra & Clorp. & $\lambda$-cial. & Cip. & Delt. \\
\hline $1 *$ & Alcatra & 17,19 & 14,29 & 16,29 & 32,85 \\
2 & Água & $-2,98$ & $-5,17$ & $-4,21$ & $-0,02$ \\
3 & Fígado & 25,62 & 23,24 & 34,06 & 38,17 \\
4 & Leite & 7,02 & 6,77 & 16,11 & 45,05 \\
5 & Maçã & 2,27 & $-16,71$ & $-18,23$ & $-20,30$ \\
6 & Solo & 3,50 & $-5,76$ & $-6,13$ & $-8,28$ \\
7 & Mel & 5,79 & $-9,38$ & $-11,65$ & $-11,95$ \\
8 & Batata & 11,71 & 15,27 & 18,38 & 19,53 \\
9 & Tomate & 9,86 & 102,8 & 162,3 & 301,6 \\
\hline
\end{tabular}

*Esses números se referem às identificações dos extratos no ACP das Figuras 1 e 2 .

Os dados da Tabela 2 foram utilizados para construir a análise de componentes principais (Figura 1).

Pode-se observar na Figura 1 que a componente principal 1 (CP1) explicou 77,4\% da variância total, e mostrou que o aumento da resposta dos piretroides $\lambda$-cialotrina, cipermetrina e deltametrina
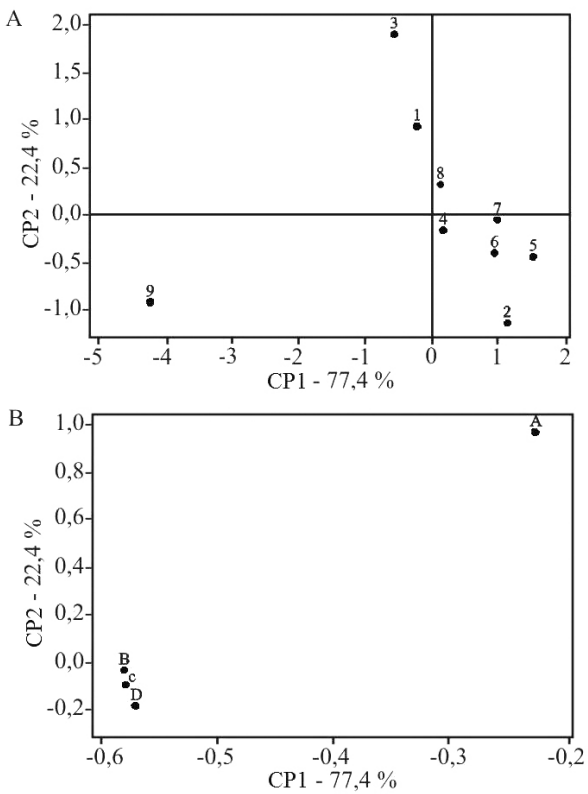

Figura 1. Escores normalizados (A) e pesos (B) de amostras como função da variação da resposta cromatográfica dos agrotóxicos (A. clorpirifós, $B$. $\lambda$ cialotrina, C. cipermetrina e D. deltametrina). Identificações das amostras: 1 . alcatra, 2. água, 3. fígado, 4. leite, 5. maçã, 6. maçã, 7. solo, 8. batata, 9. tomate
(B, C e D, respectivamente) é responsável pela separação de extratos de tomate (9) dos demais extratos. O aumento da resposta cromatográfica destes agrotóxicos, devido à saturação do CG com extratos de tomate, variou entre 100 e $300 \%$, dependendo do tempo de retenção do piretroide. Provavelmente, isso se deve à competição por sítios de adsorção no sistema cromatográfico entre carotenoides e agrotóxicos. Para os demais extratos o aumento da resposta dos piretroides variou entre 0 e $45 \%$ (Tabela 2).

Um significativo aumento da resposta do clorpirifós (> 25\%) em extratos de fígado (3) foi observado em relação aos demais tipos de amostras, o qual é mostrado pela CP2 (22,4\% de variância). Esse aumento da resposta cromatográfica foi o que influenciou no distanciamento desse extrato dos demais (Figura 1). Extratos de alcatra (1) e fígado (3) estão agrupados no mesmo quadrante, pois apresentam composição química semelhante, ${ }^{36}$ porém, extratos de alcatra proporcionaram um efeito de matriz menor para os agrotóxicos.

Os extratos de água (2), maçã (5), solo (6) e mel (7) formaram um subgrupo caracterizado pela redução da resposta cromatográfica (efeito de matriz negativo), principalmente para os piretroides. A água é considerada uma matriz simples, apresentando variação da resposta cromatográfica inferior a 5,2\% para todos os agrotóxicos. O solo, embora seja considerado uma amostra complexa, apresentou extratos claros quando submetidos à ESL-PBT, proporcionando variação da resposta inferior a 8,3\% para os piretroides. As amostras de maçã e mel apresentaram extratos com maiores quantidades de componentes endógenos, dessa forma estes interferentes proporcionaram reduções efetivas da resposta cromatográfica dos piretroides, principalmente em extratos de maçã (aproximadamente - 20\%).

Os extratos da batata (8) e do mel (7) são ricos em carboidratos. $\mathrm{O}$ extrato da batata apresenta em sua composição química o amido (polissacarídeo), sendo observado um efeito de matriz positivo para os quatro agrotóxicos. Já o extrato do mel é constituído basicamente por carboidratos mais simples (monossacarídeos como glicose e frutose), sendo observado um efeito de matriz negativo. Logo os extratos de batata e mel estão em quadrantes diferentes (Figura 1).

Extratos de leite (4) proporcionaram aumento da resposta cromatográfica para os quatro agrotóxicos (Tabela 2). Estes extratos apresentam em sua composição coextrativos lipofílicos de elevada temperatura de ebulição, como os lipídeos. Entretanto, estes compostos não impediram a adsorção dos agrotóxicos como os constituintes químicos do extrato de tomate (9). Mesmo apresentando um efeito positivo nas respostas para os quatro agrotóxicos, a ACP agrupou esse extrato junto com os extratos de solo, maçã e água, que têm efeito negativo. Provavelmente, este agrupamento foi devido à semelhança dos efeitos causados por estas matrizes na resposta do clorpirifós.

Os dados obtidos na Tabela 2 também foram utilizados para a análise hierárquica de agrupamentos (AHA) como pode ser observado na Figura 2.

A análise de agrupamento hierárquico permitiu confirmar os resultados obtidos pela análise de componentes principais e, também, visualizar os agrupamentos que não ficaram evidentes (Figura 2). Por exemplo, os extratos das amostras 1, 4 e 8 (alcatra, leite e batata) apresentaram o mesmo índice de similaridade, embora na análise do ACP estas se apresentassem em quadrantes diferentes. Esses extratos apresentaram efeito de matriz positivo inferior a $45 \%$ para os quatro agrotóxicos. A separação do extrato de tomate (9) das demais confirmou o alto efeito de matriz introduzido pelos constituintes químicos do tomate. Também foi evidenciado que extratos de amostras que reduzem a resposta cromatográfica tendem a se agrupar (2, 5, 6 e 7$)$.

\section{Curvas analíticas}

Curvas analíticas preparadas em solvente

Para uma análise minuciosa do efeito de matriz, foram construí- 


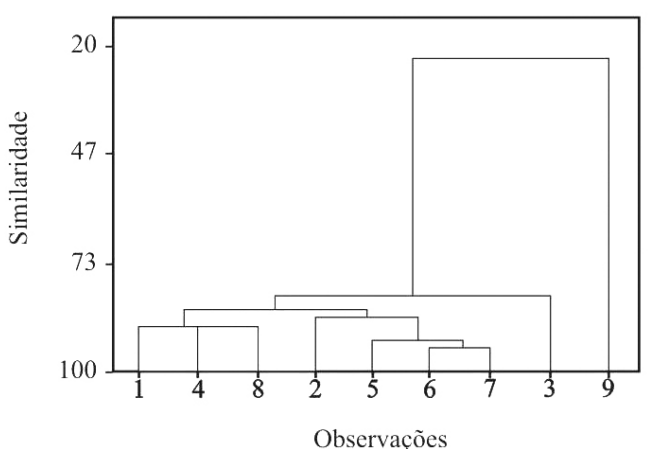

Figura 2. Dendrograma construído com os dados autoescalonados da variação da resposta dos agrotóxicos após saturação do CG. Identificações das amostras: 1. alcatra, 2. água, 3. fígado, 4. leite, 5. maçã, 6. maçã 7. solo, 8. batata, 9. tomate

das curvas analíticas a partir de soluções padrão dos agrotóxicos, em acetonitrila, nas concentrações de 5; 10, 20; 50; 100; 300 e $500 \mu \mathrm{g} \mathrm{L}^{-1}$. Estas soluções foram analisadas em 9 dias diferentes para se verificar a variação da resposta do CG-DCE com o uso do aparelho. Na Figura 3 são apresentados os coeficientes de variação obtidos para cada concentração dos quatro agrotóxicos analisados.

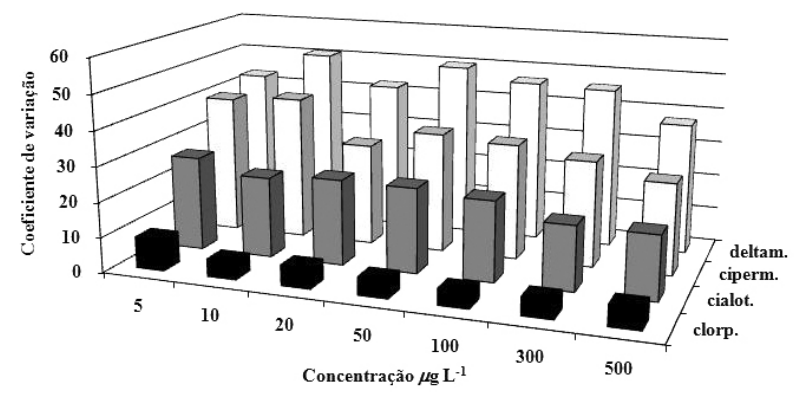

Figura 3. Coeficientes de variação das áreas (agrotóxico/padrão interno) dos agrotóxicos clorpirifós, $\lambda$-cialotrina, cipermetrina e deltametrina, analisados em 9 dias diferentes, nas concentrações 5; 20; 50; 100; 300 e $500 \mu \mathrm{g} \mathrm{L} \mathrm{L}^{-1}$

Os coeficientes de variação foram em média 6, 22, 33 e 45\% para os agrotóxicos clorpirifós, $\lambda$-cialotrina, cipermetrina e deltametrina, respectivamente. Vale destacar que quanto maior é o tempo de retenção dos agrotóxicos maior é o coeficiente de variação.

\section{Curvas analíticas preparadas em extratos das matrizes}

Foram construídas curvas analíticas para se avaliar o efeito dos coextrativos na resposta dos agrotóxicos. Para isso, soluções padrão preparadas em solvente e em extrato de matriz foram analisadas na faixa de concentração de 5 a $500 \mu \mathrm{g} \mathrm{L}{ }^{-1}$.

Na comparação entre as duas curvas analíticas (solvente e extrato de matriz), quando somente o coeficiente angular varia os componentes da matriz contribuem para introduzir nos resultados um erro sistemático proporcional. Quando apenas o coeficiente linear varia, significa que existe um erro sistemático constante. ${ }^{15}$

Para os quatro agrotóxicos analisados, observou-se que as curvas analíticas se diferenciam tanto pelo coeficiente angular quanto linear. Isso pode ser verificado na Tabela 3 , em que é apresentada a razão entre os coeficientes angulares (RCA) e lineares (RCL) das curvas analíticas obtidas em extratos da matriz e em solvente.

A razão entre os coeficientes angulares (extrato da matriz e solvente) indicou o erro associado ao efeito de matriz para cada agrotóxico. Quando a razão foi superior a 1,0 o efeito de matriz foi positivo, enquanto que valor inferior a 1,0 indicou efeito de matriz negativo. Para concentrações
Tabela 3. Razão entre os coeficientes angulares (RCA) e lineares (RCL) das curvas analíticas obtidas em extratos da matriz e em solvente puro

\begin{tabular}{lcccccccc}
\hline \multirow{2}{*}{ Amostra } & \multicolumn{3}{c}{ Clorpirifós } & \multicolumn{2}{c}{$\lambda$-Cialotrina } & \multicolumn{2}{c}{ Cipermetrina } & \multicolumn{2}{c}{ Deltametrina } \\
& RCA & RCL & RCA & RCL & RCA & RCL & RCA & RCL \\
\hline Água & 1,00 & 1,01 & 1,08 & 0,96 & 1,00 & 2,50 & 1,00 & 0,97 \\
Alcatra & 1,18 & 1,24 & 1,29 & 1,51 & 1,63 & 2,65 & 2,17 & 1,15 \\
Batata & 1,30 & 1,17 & 1,38 & 1,07 & 1,63 & 1,41 & 2,50 & 0,15 \\
Fígado & 1,25 & 1,69 & 1,54 & 1,39 & 2,14 & 3,39 & 4,00 & 1,90 \\
Leite & 1,20 & 1,08 & 1,33 & 2,34 & 1,71 & 2,19 & 2,40 & 2,35 \\
Maçã & 1,00 & 1,36 & 0,93 & 1,30 & 0,80 & 0,25 & 0,78 & 0,70 \\
Mel & 1,10 & 0,96 & 1,43 & 1,71 & 2,00 & 0,98 & 3,00 & 1,71 \\
Tomate & 1,27 & 1,03 & 1,46 & 1,44 & 2,00 & 2,38 & 2,80 & 2,87 \\
Solo & 1,00 & 1,14 & 0,93 & 1,69 & 0,89 & 0,03 & 0,88 & $-0,41$ \\
\hline
\end{tabular}

mais altas dos agrotóxicos $\left(500 \mu \mathrm{g} \mathrm{L}^{-1}\right)$, a porcentagem de variação da resposta de cada agrotóxico foi estimada pelos coeficientes angulares [(RCA -1) x100]. Por exemplo, para o clorpirifós a variação da resposta foi de $0 ; 18 ; 30 ; 25 ; 20 ; 0 ; 10 ; 27$ e $0 \%$ na presença dos extratos das matrizes água, alcatra, batata, fígado, leite, maçã, mel, tomate e solo, respectivamente.

Esses mesmos resultados podem ser evidenciados na Figura 4, em que foi determinada a porcentagem de variação da resposta cromatográfica para os quatro agrotóxicos em extratos das nove matrizes [\% = $\left.\left(\overline{\mathrm{A}}_{\text {matriz }}-\overline{\mathrm{A}}_{\text {solvente }}\right) / \overline{\mathrm{A}}_{\text {solvente }} \mathrm{x} 100\right]$.

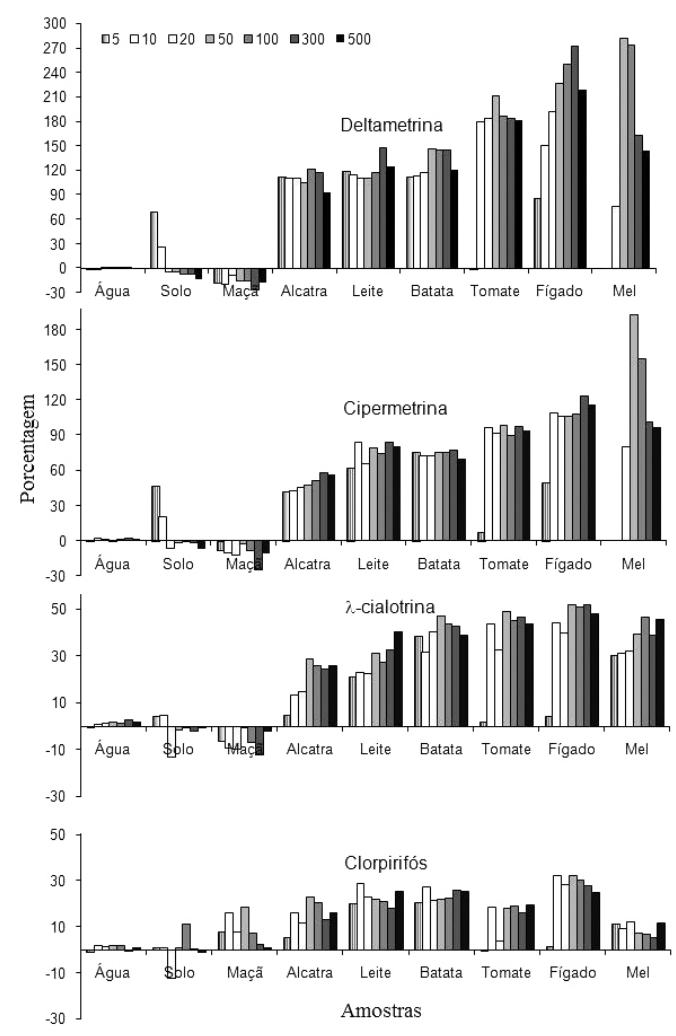

Figura 4. Porcentagem de variação da resposta cromatográfica dos agrotóxicos clorpirifós, $\lambda$-cialotrina, cipermetrina e deltametrina quando preparados em extratos (água, solo, maçã, alcatra, leite, batata, tomate, fígado e mel) em relação às preparadas em solvente puro nas concentrações de 5, 10, 20, 50, 100, 300 e $500 \mu \mathrm{g} \mathrm{L}$

Observa-se na Figura 4 o baixo efeito de matriz introduzido pelos componentes dos extratos de água e solo. Resultados semelhantes foram observados quando os sítios ativos do sistema cromatográfico foram saturados com esses extratos (Tabela 2). 
Para os piretroides, os constituintes químicos do extrato da maçã promoveram uma redução da resposta cromatográfica, diferente do que ocorreu com o clorpirifós que apresentou efeito de matriz positivo. Esse comportamento diferenciado das respostas dos agrotóxicos na presença dos constituintes da maçã dificulta o uso de analitos protetores, bem como o uso de padrão interno, como forma de minimizar os erros que ocorrem nas análises cromatográficas.

Segundo Hajslová et al. ${ }^{2}$ o efeito de matriz é maior em baixas concentrações de agrotóxicos. Entretanto, resultados obtidos neste trabalho e, principalmente, nas análises de deltametrina em extrato de fígado (Figura 4) mostram que o efeito de matriz aumentou com a concentração dos agrotóxicos.

Para deltametrina e cipermetrina não foi possível determinar a área nas concentrações de 5 e $10 \mu \mathrm{g} \mathrm{L}^{-1}$ preparadas em acetonitrila e extratos de mel, devido à baixa detectabilidade do aparelho nessas condições. Ambas as curvas analíticas foram obtidas após injeções sucessivas de extratos de mel no CG-DCE. Embora a saturação do CG com extratos de mel favoreça a diminuição da resposta cromatográfica dos agrotóxicos (Tabela 2), observou-se que as curvas analíticas desse extrato proporcionaram maior resposta quando comparadas em solvente (Figura 4).

De forma geral, o efeito de matriz estimado pela razão entre os coeficientes angulares apresentou a seguinte ordem crescente para os piretroides: água $<$ solo $<$ maçã $<$ alcatra $<$ leite $<$ batata $<$ tomate $<$ mel $<$ fígado. Observou-se que esta ordem é ligeiramente diferente da sequência esperada pelos dados da Tabela 2. Isso sugere que as características do efeito de matriz podem ser diferentes quando se considera: apenas o efeito da saturação do CG; o efeito da injeção de extratos contendo simultaneamente componentes da matriz e agrotóxicos. Também foi observado que para todas as amostras a ordem crescente de efeito de matriz foi clorpirifós $<\lambda$-cialotrina $<$ cipermetrina $<$ deltametrina.

Não foi observado em nenhum cromatograma sinais de degradação dos agrotóxicos promovidos por componentes das matrizes. Entretanto, coextrativos do leite promoveram instabilidade da linha de base, apresentando muitos ruídos.

\section{CONCLUSÃO}

As análises quimiométricas (ACPe AHA) mostraram-se ferramentas úteis no estudo do efeito de matriz (saturação do CG) para quatro agrotóxicos. Os componentes das matrizes batata, alcatra, leite, fígado e tomate proporcionaram aumento da resposta cromatográfica dos agrotóxicos; em contrapartida, extratos orgânicos de água, solo, maçã e mel promoveram pequena variação ou redução das respostas cromatográficas. Os componentes do tomate destacaram-se por aumentarem expressivamente o sinal dos piretroides após a saturação do CG.

Neste trabalho, a comparação das curvas analíticas preparadas em solvente e extratos apresentou ordem crescente de efeito da matriz de acordo com o aumento da complexidade da matriz (água $<$ solo $<$ maçã $<$ alcatra $<$ leite $<$ batata $<$ tomate $<$ fígado $<$ mel) para a maioria dos agrotóxicos. A ordem crescente de variação da resposta cromatográfica dos agrotóxicos foi de acordo com o tempo de retenção (clorpirifós < $\lambda$-cialotrina $<$ cipermetrina $<$ deltametrina)

Estudos futuros ainda são necessários para se investigar a relação entre um maior número de agrotóxicos e componentes de diversas matrizes durante as análises cromatográficas, empregando as técnicas quimiométricas.

\section{REFERÊNCIAS}

1. Renévan der Hoff, G.; van Zoonen, P.; J. Chromatogr., A 1999, 843, 301.

2. Hajslová, J.; Holadova, K.; Kocourek, V.; Poustka, J.; Godula, M.; Cuhra, P.; Kempny, M.; J. Chromatogr., A 1998, 800, 283.
3. Erney, D. R.; Gillespie, A. M.; Gilvydis, D. M.; J. Chromatogr, A 1993, 638, 57.

4. Sanchez-Brunete, C.; Albero, B.; Martín. G.; Tadeo, J. L.; Anal. Sci. 2005, $21,129$.

5. Schenck, F. J.; Lehotay, S. J.; J. Chromatogr., A 2000, 868, 51.

6. Hajslová, J.; Zrostlikova, J.; J. Chromatogr.. A 2003, 1000, 181.

7. Zrostikova, J.; Hajslova, J.; Godula, M.; Mastovska, E.; J. Chromatogr., A 2001, 937, 73 .

8. Pereira, A. S.; Aquino Neto, F. R.; Quim. Nova 2000, 23, 370.

9. Godula, M.; Hajslová, J.; Mastovska, K.; Krivanková, J.; J. Sep. Sci. 2001, 24,355 .

10. Rantakokko, P.; Yritys, M.; Vartiainen, T.; J. Chromatogr., A 2004, 1028, 179.

11. Anastassiades, M.; Mastovská, K.; Lehotay, S. J.; J. Chromatogr., A 2003, 1015, 163.

12. Erney, D. R.; Poole, C. F.; J. High Resolut. Chromatogr. 1993, 16, 501.

13. Kirchner, M.; Huskova, R.; Matisova, E.; Mocak, J.; J. Chromatogr., A 2008, 1186, 271.

14. Gonzáles, F. J. E.; Torres, M. E. H.; López, E. A.; Cuadros-Rodriguez, L.; Vidal, J. L. M.; J. Chromatogr, A 2002, 996, 155.

15. Cuadros-Rodriguez, L.; García-Campana, A. M.; Almansa-López, E.; EgeaGonzáles, F. J.; Cano, M. L. C.; Frenich, A. G.; Marínez-Vidal, J. L., Anal. Chim. Acta 2003, 478, 281.

16. Lehotay, S. J.; Eller, K. I.; J. AOAC Int. 1995, 78, 821.

17. Menkissoglu-Spiroudi, U.; Fotopoulou, A.; Int. J. Environ. Anal. Chem. 2004, 84, 15.

18. Erney, D. R.; Pawlowski, T. M.; Poole, C. F.; J. High Resolut. Chromatogr. 1997, 20, 375.

19. Jimenez, J.; Bernal, J.; Del Nozal, M.; Toribio, L.; Arias, E.; J. Chromatogr, A 2001, 919, 147.

20. Jimenez, J. J.; Bernal, J. L.; del Nozal, M. J.; Martın, M. T.; Mayo, R.; J. Chromatogr, A 2008, 1187, 40.

21. Rossia, S.; Dalperoa, A. P.; Ghinia, S.; Colombob, R.; Sabatinib, A. G.; Girottia, S.; J. Chromatogr., A 2001, 905, 223.

22. Barker, S. A.; J. Chromatogr., A 2000, $880,63$.

23. Barker, S. A.; J. Chromatogr., A 2000, 885, 115.

24. Goulart, S. M.; Queiroz, M. E. L. R.; Neves, A. A.; Queiroz, J. H.; Talanta 2008, 75, 1320.

25. Pinho, G. P.; Neves, A. A.; Queiroz, M. E. L. R.; Silvério, F. O.; Food Chem. 2010, 121, 251.

26. Gonzalez-Rodriguez, R. M.; Rial-Otero, R.; Cancho-Grande, B.; SimalGandara, J.; Food Chem. 2008, 107, 1342.

27. Mastovska, K.; Lehotay, S. J.; Anastassiades, M.; Anal. Chem. 2005, 77, 8129.

28. Pinho, G. P.; Neves, A. A., Queiroz, M. E. L. R., Silvério, F. O.; Quim. Nova 2009, 32, 987

29. Przbylski, C.; Hommet, F.; J. Chromatogr., A 2008, 1201, 78.

30. Ferreira, M. M. C.; Antunes, A. M.; Melgo, M. S.; Volpe, P. L. O.; Quim. Nova $1999,22,724$

31. Vieira, H. P., Neves, A. A., Queiroz, M. E. L. R.; Quim. Nova 2007, 30, 535.

32. Pinho, G. P.; Neves, A. A., Queiroz, M. E. L. R., Silvério, F. O.; Food Control, no prelo.

33. Dardengo, R. P.; Dissertação de Mestrado, Universidade Federal de Viçosa, Brasil, 2007.

34. Silva, E. P.; Dissertação de Mestrado, Universidade Federal de Viçosa, Brasil, 2008

35. Pussente, I. C.; Dissertação de Mestrado, Universidade Federal de Viçosa, Brasil, 2008.

36. TACO -Tabela Brasileira de Composição de Alimentos, versão $2-2^{\text {a }}$ ed., 2006, Núcleo de Estudos e Pesquisas em Alimentação, Universidade Estadual de Campinas. 